their position is not clear, but they appear to have entered at the central necrotic area of the lesion.

Analogous observations referring to bronchial ciliated epithelium in the first case and bile-duct epithelium in the second are recorded by Foà and Lubarsch. ${ }^{1}$ The condition is very curious, as these structures have no close relationship to the blood-stream such as is seen in the well-known embolism of bone marrow and placental cells.

Summary.-Clinically the case was one of acute illness, terminating fatally within twenty-four hours, the prominent features of which were headache, cerebral irritation manifesting itself in restlessness, delirium, and finally convulsions. There was also slight abdominal tenderness which might have suggested peritonitis, but there was no pyrexia. The history afforded no hint as to the nature of the disease. At the post-mortem examination the case presented the features of an acute septicæmia and early peritonitis, which appeared to spread from a hæmorrhagic lesion of the small intestine, with ulceration and necrosis internally and signs of an infective process extending up the mesentery. The nervous phenomena were explained by the discovery of a diffuse hæmorrhagic condition of the pia-arachnoid, which microscopical examination demonstrated to be an early meningitis due to the bacillus anthracis. The identity of the organism was proved by cultivation and inoculation experiments. The intestinal lesion was clearly the oldest, and the conclusion appears fully warranted that the case was anthrax septicæmia due to intestinal infection, caused most probably by the ingestion of a quantity of anthrax bacilli or spores in food.

\title{
THE BACTERIOLOGICAL EXAMINATION OF MILK. ${ }^{2}$
}

By Dr A. C. Houston.

THE main object of the present investigation was to determine the biological qualities of London milks, and also to see whether bacteriological tests could advantageously be used to aid the administrator in his efforts to bring about a gradual improvement in the biological qualities of the milk supplied to London.

Five series of experiments were carried out.

Series I. Specially collected milk from twenty separate healthy cozes. (Samples I-20.)-In the first series the whole of the milk (exclusive of the "fore-milk") from each of twenty separate healthy cows was in each case collected in a clean pail. The milk was next strained through a clean strainer into a second clean pail. After stirring with a sterile glass rod, a portion of the milk was poured into a sterile glass-stoppered bottle. The bottle was placed in a box containing ice, conveyed rapidly to the laboratory, and examined immediately. Before milking, the cows' udders and teats were washed, and the milker washed his hands and put on a clean blouse. No unreasonable precautions were taken; they were simply those which attention to the ordinary rules of cleanliness would naturally suggest.

Series II. Tzenty samples of milk collected from purveyors' shops. (Samples $21,22,25,26,27,28,29,30,3 \mathrm{I}, 32,33,34,35,39,40,4 \mathrm{I}, 42,43,44,45$.) They were collected in sterile bottles, iced, conveyed rapidly to the laboratory, and examined immediately. The local conditions were frequently most unsatisfactory.

Series III. Twenty samples of milk collected from dairy shops. (Samples

1 Foà and Lubarsch : "Lubarsch's Allgemeine Pathologie," 1905, Band i., Part I., p. 250.

2 From a Report embodying the results of an inquiry carried ont by the author for the London County Council. The complete Report (price 2s.) may be obtained from Messrs King \& Son, 2 Great Smith Street, Victoria Street, Westminster, S. W. 
$23,24,36,37,38,46,47,48,49,50,51,52,53,54,55,56,57,58,59,60)$. Not uncommonly, the local conditions were far from satisfactory.

Series $I V$. Treenty samples of milk collected from churns at railz'ay stations. (Samples 6r-80.)

Series $V$. Twenty samples of milk collected from the establishments of wellknown milk dealers. (Samples 8I-100.) -In this series twenty samples of milk were collected from well-known milk dealers credited (rightly or wrongly) with taking special precautions to ensure the purity of the milk supplied by them.

The first series of samples may be regarded as "controls" to the second, third, fourth, and fifth series.

The tests applied were as follows :-

Primary reading (by volume) of the apparent filth in milk.

Secondary reading (by volume) of the apparent filth in milk.

Microscopical examination of the sediment.

B. coli test.

Streptococcus test.

B. enteritidis sporogenes test.

Together with study of :-

(a) The biological attributes of the B. coli (or coli-like microbes), isolated from the various samples of milk.

(b) The biological attributes of the streptococci isolated from the various samples of milk.

(c) The bacteriology of "fore" milk.

(d) The effect of keeping milk at a low temperature.

SUMMARY OF RESULTS.

Percentage Results in B. Enteritidis Sporogenes Test.

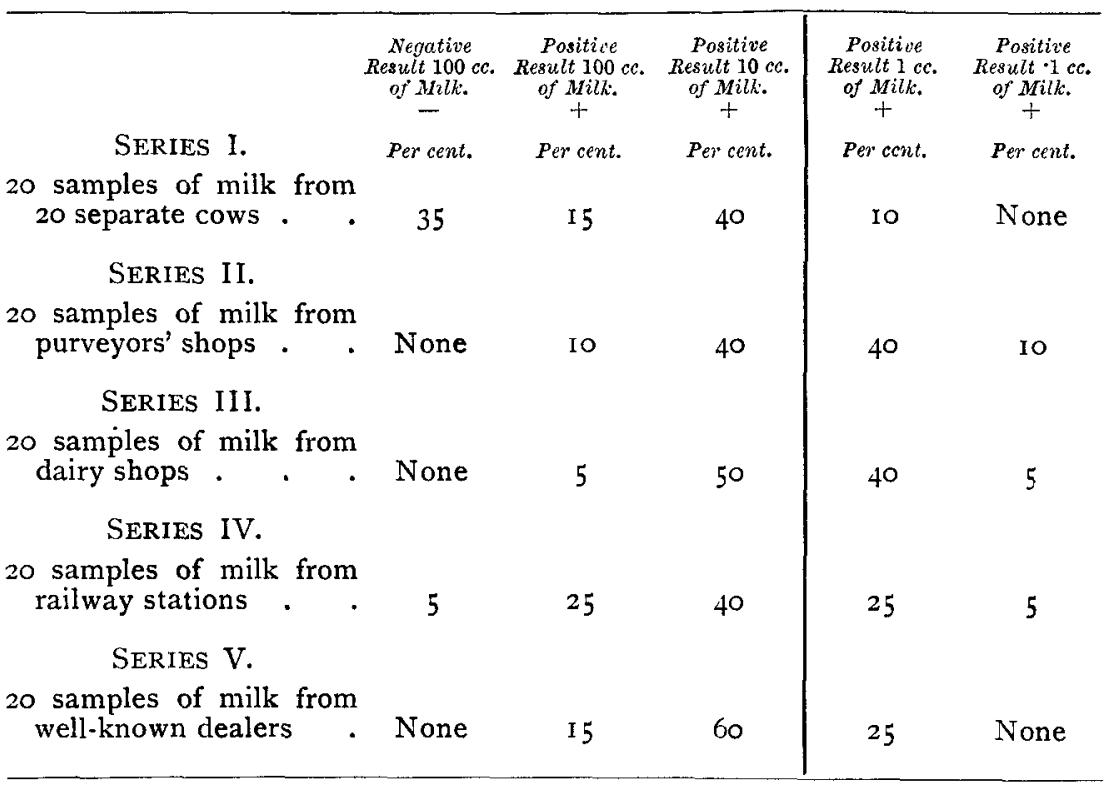

It is apparent that the samples of milk belonging to Series I. were the most satisfactory; Series IV. and V. come next in order of merit, and Series II. and III. were least satisfactory.

The perpendicular line refers to a provisional standard for comparative purposes. Samples on the right side of the line infringe the standard. 
SERIES I.

20 samples of milk from 20 separate cows.

SERIES II.

20 samples of milk from purveyors' shops

SERIES III.

20 samples of milk from dairy shops

\section{SERIES IV.}

20 samples of milk from railway stations

SERIES V.

20 samples of milk from well-known dealers

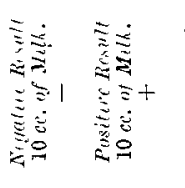

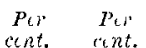

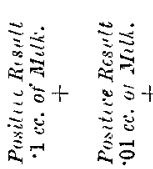

.

30 to $25 \quad 5$ None

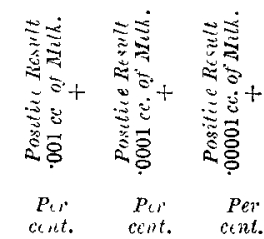

None None None

25

Io None - $\quad-\quad$ I $5 \quad 35$

25 I 5 IO

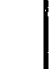
- None

$25-15$

Io 5 None

It is obvious that the samples of milk belonging to Series 1 . were much the most satisfactory; next comes Series IV.; next Series V., and Series II. and III. were about equally unsatisfactory.

The perpendicular line refers to a provisional standard for comparative purposes. Samples on the right side of this line infringe the standard.

\section{Percentage Results in Primary Reading of Sediment in Milk.} (Parts per million, by volume).

SERIES I.

\begin{tabular}{|c|c|c|c|}
\hline 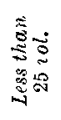 & 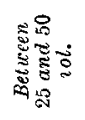 & 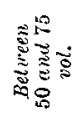 & 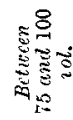 \\
\hline $\begin{array}{c}\text { Per } \\
\text { cent. }\end{array}$ & $\begin{array}{c}P_{e r} \\
\text { cent. }\end{array}$ & $\begin{array}{l}\text { Per } \\
\text { cent. }\end{array}$ & $\begin{array}{l}\text { Per } \\
\text { cent. }\end{array}$ \\
\hline
\end{tabular}

\begin{tabular}{|c|c|c|c|}
\hline 胥 & 号 & 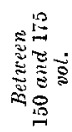 & 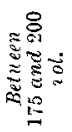 \\
\hline $\begin{array}{c}P e r \\
\text { cent. }\end{array}$ & $\begin{array}{c}P e r \\
\text { cent. }\end{array}$ & $\begin{array}{c}P_{c e r} \\
\text { cent. }\end{array}$ & $\begin{array}{c}\text { Per } \\
\text { cert. }\end{array}$ \\
\hline
\end{tabular}

20 samples of milk from 20 separate cows

\section{SERIES II.}

20 samples of milk from purveyors' shops.

SERIES III.

20 samples of milk from dairy shops .

SERIES IV.

20 samples of milk from railway stations

SERIES V.

2o samples of milk from well-known dealers

Series I. claims first place ; then comes Series V.; next Series IV., and Series II. and III. were both unsatisfactory, but Series II. was on the whole the least satisfactory.

The perpendicular line refers to a provisional standard for comparative purposes. Samples on the right side of this line infringe the standard. 
Percentage Results in Secondary Reading of Sediment in Milk.

(Parts per million, by volume).

SERIES I.

\begin{tabular}{|c|c|c|c|c|c|c|c|c|}
\hline 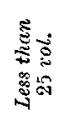 & 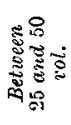 & 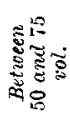 & 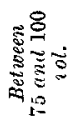 & 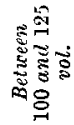 & 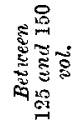 & 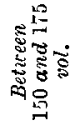 & 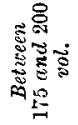 & \begin{tabular}{l} 
怘 \\
\multirow{2}{*}{} \\
0 \\
0
\end{tabular} \\
\hline $\begin{array}{l}\text { Per } \\
\text { eent. }\end{array}$ & $\begin{array}{c}\text { Per } \\
\text { cent. }\end{array}$ & $\begin{array}{c}\text { Per } \\
\text { cent. }\end{array}$ & $\begin{array}{c}P e r \\
\text { cent. }\end{array}$ & $\begin{array}{c}P e v \\
\text { cent. }\end{array}$ & $\begin{array}{c}\text { Per } \\
\text { cent. }\end{array}$ & $\begin{array}{l}P e r \\
\text { cent. }\end{array}$ & $\begin{array}{c}\text { Per } \\
\text { cent. }\end{array}$ & $\begin{array}{c}P e r \\
\text { cent. }\end{array}$ \\
\hline
\end{tabular}

20 samples of milk from 20 separate cows .

SERIES II.

2o samples of milk from purveyors' shops .

SerIES III.

20 samples of milk from dairy shops

SERIES IV.

20 samples of milk from railway stations .

SERIES V.

20 samples of milk from well known dealers

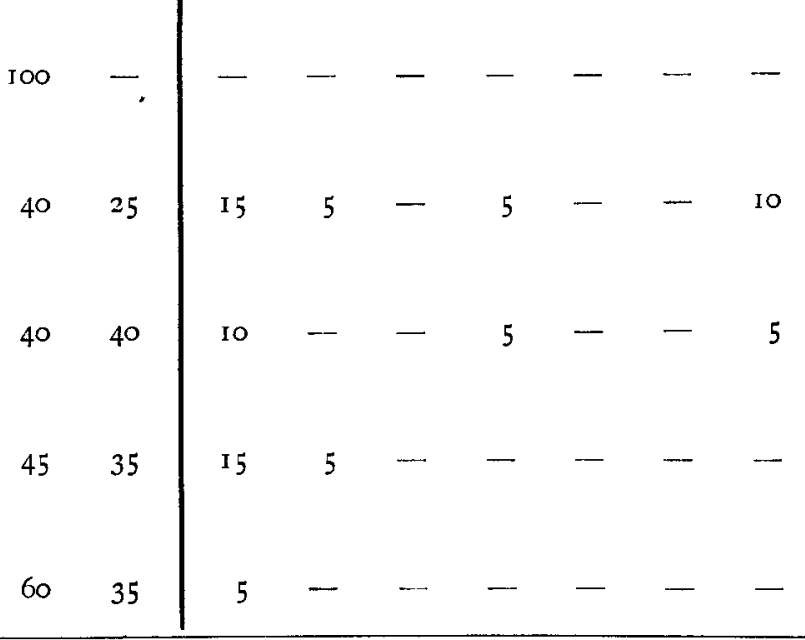

It is obvious that Series 1. comes first in order of merit ; next comes Series V.; next Series IV., and last Series II. and III., but on the whole Series II. was the most unsatisfactory.

The perpendicular line refers to a provisional standard for comparative purposes. Samples on the right side of this line infringe the standard.

In summary of the foregoing results (primary and secondary readings), on the whole it may be said that Series I. was undoubtedly far the best; Series IV. and V. yielded somewhat similar results and come next in order of merit; and Series 1I. and III. were unquestionably the least satisfactory.

\section{STREPTOCOCCI.}

Milk from 20 separate Cowes. Series $I$.

In $8(40 \%)$ samples $\left(\mathrm{I}, 3,4,5, \mathrm{IO}, \mathrm{r}_{4}, \mathrm{r} 7,20\right)+\mathrm{r} / \mathrm{rooth}$ cc.

In $6(30 \%) \quad, \quad(2,7,9,13,15,19)+1 /$ I oth negatve $1 /$ Iooth $\mathrm{cc}$.

In $4(20 \%) \quad, \quad(8, \mathrm{II}, \mathbf{I} 2, \mathbf{1} 8)$ none in $1 / 1$ oth cc.

In $2(10 \%) \quad, \quad(6,16)$ none in $1 / 100$ th, query negative $1 /$ Ioth $\mathrm{cc}$.

\section{Milk from Purveyors' Shops. Series II.}

In I $(5 \%)$ samples $(25)$ query positive result I/ I0,00oth $\mathrm{cc}$.

In $\mathrm{I}(5 \%), \quad(39)$ present in $\mathrm{r} / \mathrm{I} 0$, oooth $\mathrm{cc}$.

In $8(40 \%) \quad " \quad(2 \mathrm{I}, 28,30,32,33,4 \mathrm{I}, 44,45)+\mathrm{I} / \mathrm{roooth}$ negative I/10,00oth cc.

In $3(15 \%) \quad, \quad(26,27,29)$ query $+1 /$ 100oth negative $1 / 10,000$ th $\mathrm{cc}$.

In $5(25 \%) \quad, \quad(3 \mathrm{I}, 35,40,42,43)+\mathrm{I} / \mathrm{I}$ ooth $\mathrm{cc}$. negative $\mathrm{I} / \mathrm{I}$ oooth $\mathrm{cc}$.

In I $(5 \%), \quad(22)$ query $+\mathrm{I} / \mathrm{rooth}$, negative $\mathrm{I} / 1000$ th $\mathrm{cc}$.

In I $\left(5^{\circ},\right) \quad, \quad(34)$ query negative $1 /$ rooth cc. 
Milk from Dairy Shops. Series III.

In $3(15 \%)$ samples $(49,52,57)+\mathrm{I} / 10,000$ th $\mathrm{cc}$.

In $8(40 \%) \quad " \quad(36,37,38,46,48,53,59,60)+1 / 1000$ th negative I/ I0,000th cc.

In $2(10 \%) \quad, \quad(23,24)$ none in $\mathrm{I} /$ roooth cc.

In $3(15 \%) \quad " \quad(47,50,55)+1 / 100$ th negative $\mathrm{r} / 1$ roooth $\mathrm{cc}$.

In $4(20 \%) \quad, \quad\left(5 \mathrm{I}, 54,56,5^{8}\right)$ query negative $\mathrm{I} / \mathrm{1}$ ooth cc.

Milk from Railway Stations. Series $I V$.

In $2(10 \%)$ samples $(66,73)+1 /$ ro, oooth cc.

In $5(25 \%), \quad, \quad(65,74,78,79,80)+\mathrm{I} /$ roooth negative $\mathrm{I} / \mathrm{I} 0,000$ th $\mathrm{cc}$.

In $3(15 \%) \quad, \quad(67,72,76)+1 / 100$ th negative $1 /$ roooth cc.

In $10(50 \%) \quad " \quad(61,62,63,64,68,69,70,71,75,77)$ query negative I/rooth cc.

Milk from well knozon Dealers. Series $V$.

In $4(20 \%)$ samples $(89,91,95,100)+\mathrm{r} / \mathrm{1} 0,000$ th cc.

In $9\left(45^{\circ} \%\right) \quad " \quad(81,83,84,86,90,92,93,94,98)+1 / 1000$ th negative I/I0,00oth cc.

In $3(15 \%) \quad, \quad(87,96,97)+\mathrm{I} /$ Iooth negative $\mathrm{I} / \mathrm{I}$ oooth $\mathrm{cc}$.

In $4(20 \%) \quad, \quad(82,85,88,99)$ query negative $1 / 100$ th $\mathrm{cc}$.

It is obvious that the samples of milk usually contained streptococci in abundance. There are a good many practical difficulties in connection with the enumeration of streptococci in milk. It commonly happens that the plates are crowded with minute colonies. Sometimes each of the sub-cultures from these colonies turns out eventually to be a streptococcus. At other times, however, as many as twenty or thirty such cultures may be made with negatiz' results, because either the cultures fail to develop any grow th on incubation or a growth of a microbe which cannot be classed as a streptococcus. It is difficult to make any accurate comparison between the number of streptococci in the samples under Series I., II., III., IV., and V. Although there can be no doubt that the smallest number of streptococci occurred in Series I., the number was sometimes so great that it would seem most undesirable to suggest any stringent numerical standard as regards this test. Unfortunately, it is a most difficult matter to sift the harmful streptococci from the streptococci which are believed to be harmless, and this circumstance militates against the value of the test. Series IV. comes next (after I.) in order of merit; but no definite distinction can safely be made between Series II., III., and V.

\section{RESULT OF MICROSCOPICAL EXAMINATION OF THE SEDIMENT.}

Milk from 20 separate cows. Series $I$.-Very little dirt; usually only a few bacilli, and definite chains of cocci (streptococci) very rare. Cocci, however, were not uncommonly present, although few in number. Pus-like cells were either absent or few in number; but some of the preparations showed the presence of a fair number of cells liable to be mistaken for pus cells. No "acid-fast" bacteria were noted.

Milk from purveyors' shops. Series II.-Many of the preparations showed the presence of much dirt, numberless cocci, and a good many bacilli. Samples 2 I, 30, 32, and perhaps more particularly samples $35,39,40,4 \mathrm{I}$, and 45 , were noteworthy in these respects. Sample 3 I contained fewer microbes but much dirt. Sample 33 appeared to contain some flour-like impurity. Definite chains of cocci (streptococci) were, relatively speaking, seldom noted. The microbes were usually either cocci or extremely short bacilli arranged often in couples and usually in masses. Samples 2 I and 34 con- 
tained some "acid-fast" bacteria not unlike the tubercle bacillus. Samples 32 and 43 contained some "acid-fast" bacteria, but these bacteria were unlike the tubercle bacillus. Some of the preparations showed the presence seemingly of yeasts and fungi. As regards pus cells, the results were apparently not unsatisfactory, although sometimes the presence of much dirt may bave "masked" the presence of pus cells. No inconsiderable proportion of the preparations contained some pus-like cells which perhaps some microscopists would have pronounced definitely to be pus cells. . But, on the whole, the opinion was formed tentatively that the "pus test" is not altogether satisfactory, and that the attempt to enumerate pus cells and either to approve or condemn milks solely on this basis is open to many obvious objections. The presence and significance of pus in milk is a matter which merits careful consideration.

Milk from dairy shops. Series III.--The general remarks (Series II.) apply to this series unless otherwise stated, particularly perhaps as regards the comparative absence of definite chains of cocci (streptococci) and the large number of cocci or very short bacilli occurring in masses. The microscopic preparations made from milk Samples 23, 24, 37, 38, 58, 59, and 6o contained some "acid-fast" bacteria; of these, the preparations from milk Samples 23, 38, 59, and 60 were observed to contain bacilli not unlike the tubercle bacillus. Many of the samples were conspicuous as regards the presence of much dirt, cocci, and bacilli.

Milk from railway stations. Series $I V$.--The general remarks (Series II. and III.) apply to this series unless otherwise stated. The microscopic preparations made from Samples $62,65,67,68,69,70,74$, and 76 contained a few "acid-fast" bacteria; of these 62,67 , and 74 were not unlike the tubercle bacillus. In Sample 80 the number of streptococci was very marked, and there was also present what appeared to be partially disintegrated pus. Relative to the amount of dirt, the cocci and bacilli seemed less numerous in this series than in Series II., III., and V.

Milk from z'ell-know'n dealers. Series $V$. - The general remarks (Series II., III., and IV.) apply to this series unless otherwise stated. The microscopic preparations made from Samples 89, 92, 94, 97 and 99 contained a few "acid-fast" bacteria ; in the case of Sample 92, the hacilli were not unlike the tubercle bacillus. Samples $82,88,89,99$ and 100 attracted notice owing to the amount of dirt or cocci, or both these matters. Sample 95 showed the presence of many streptococci, and apparently partially disintegrated pus cells were also present.

Regarding the results as a whole, the tentative conclusion was formed that the microscopic examination of the sediment of milk (even if carried out in a quantitative manner) is fraught with difficulties, and at present I am unable to suggest even a tentative standard for this test.

Still, there is no doubt that Series I. was easily first in order of merit; Series IV. and V. were less satisfactory; and Series II. and III. were about equally unsatisfactory.

\section{BACTERIOLOGICAL AND OTHER STANDARDS AS REGARDS MILK SUPPLY.}

The question of standards as regards milk supply is difficult, except in certain directions and in relation to extreme degrees of pollution. In what follows it is assumed that it would be practicable to refrigerate milk immediately after milking and preserve it at a temperature below $10^{\circ} \mathrm{C}$. during transit, and subsequently as long as it was exposed for sale. If this be considered impracticable, the standards set up for the $B$. coli and streptococcus tests would require to be greatly modified. 
Further, the standards are provisional and primarily are intended for comparative purposes. As regards legislation, if the practicability of bacteriological standards be entertained, the proposed standards, might be utilised in a variety of ways. For example, it might not be desirable to prosecute unless a sample infringed to a marked extent the standards adopted, or the local conditions were specially unfavourable, or the milk dealer habitually sold impure milk.

At present the milk dealer knows that he must conform to chemical standards to avoid prosecution ; but there is no similar inducement to regard the biological purity of milk as of first importance.

In the absence of bacteriological standards, it is difficult to see how the biological quality of milk sold in London can be gradually improved. Yet few will deny that there is much room for improvement.

Nevertheless, although I have ventured to touch on the debatable question of bacteriological standards and have even suggested tentatively for one or another test where, I think, the line might perhaps be drawn, the main purpose of this report is to set forth my results in such a way as to enable those interested in the subject to form their own conclusions as to the feasibility or otherwise of imposing bacteriological stardards.

In the following table milk is arranged in a series of classes for each separate test, according to either the amount of the sample yielding a positive reșult or the volume of the sediment; and certain lines are drawn indicating provisional standards for comparative purposes.

It is not, of course, suggested that samples of milk "passing" these standards would necessarily be "safe," or that samples infringing the same standards need of necessity be regarded as potentially dangerous to health. The standards are arbitrary and are based on the results of the examination of I oo samples of milk collected during the coldest months of the year.

The standards may, in view of the circumstances about to be related, appear unduly lenient, but it seems undesirable at present to press for any higher standard.

Milk, if directly transferred from the washed udders of healthy cows into sterile bottles, even if the "fore-milk" be included, contains in my experience no spores of B. enteritidis sporogenes in $100 \mathrm{cc}$. ; and no B. coli in Io cc. As regards streptococci, the case is somewhat different, as "fore-milk" sometimes contains streptococci in abundance, at other times these microbes are seemingly absent. 
ABSTRACTS AND REPORTS.

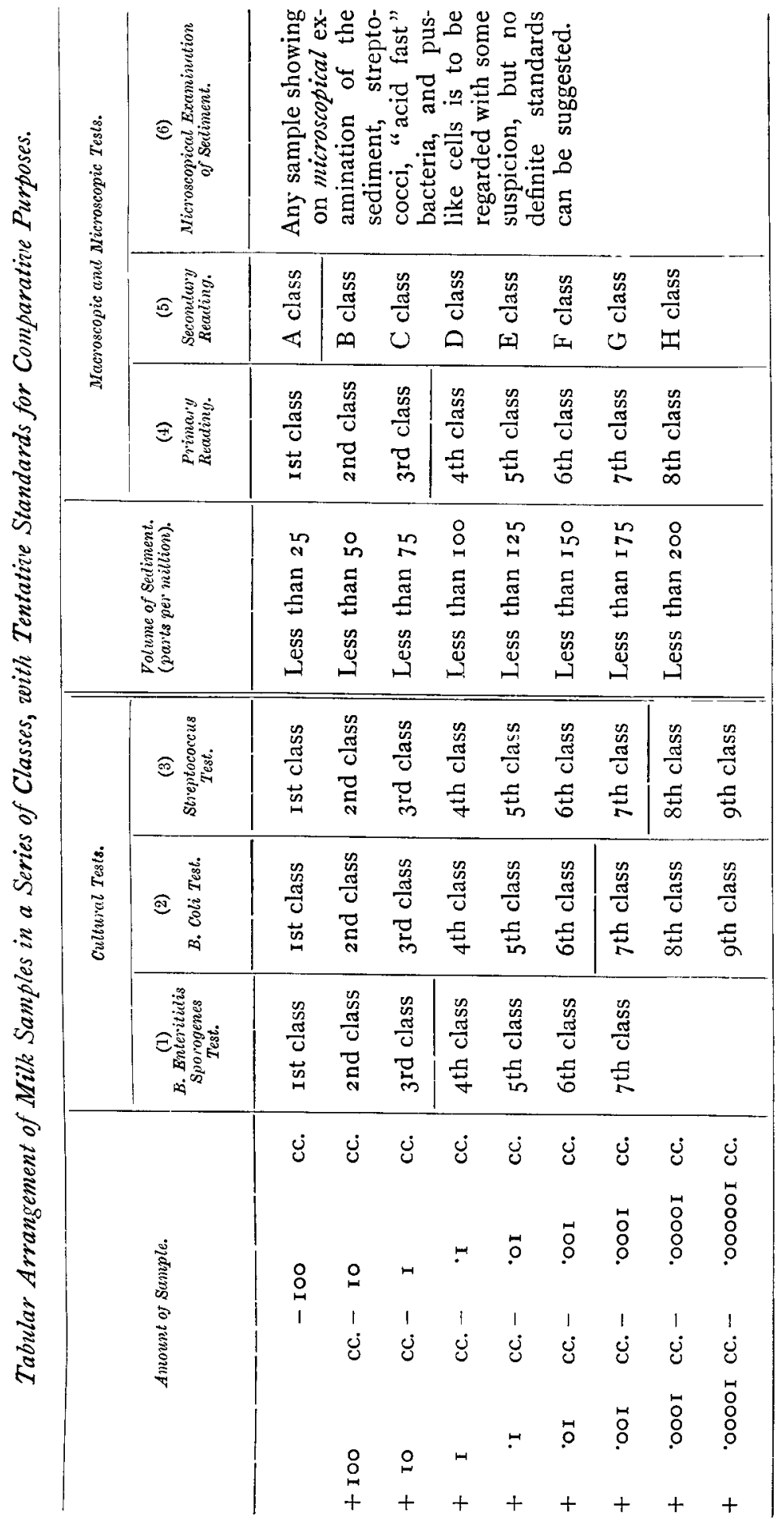


The horizontal lines refer, in each case, to provisional standards for comparative purposes. According to these tentatice standards, zelhich apply only to milk previously cooled and maintained at a temperature beloze $10^{\circ} \mathrm{C}$., samples would be objected to which infringed, with regard to the various tests, standards as follows :-
r. B. enteritidis sporogenes test
(non-multiplying + I c.c. $4^{\text {th }}$ class $\}$ factor $)$.
$+\cdot 00$ r c.c. $7^{\text {th }}$ class (multiplying
$+\circ 00$ I c.c. 8 th class $\}$ factors).
2. B. coli test
3. Streptococcus tes
4. Primary reading of volume of sediment (parts per million)
5. Secondary reading of volume of sediment (parts per million)

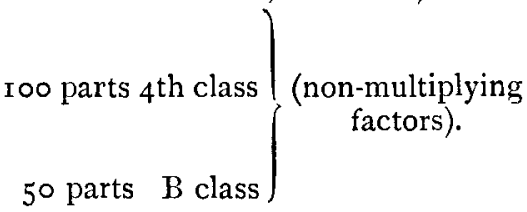

In other words, a milk should, to escape objection, yield a negative result as regards tests I, 2, 3 with I cc., I/I000 cc., and I/I0,000 cc. respectively; and as regards tests 4 and 5 the volume of sediment should be less than 100 and less than $5^{\circ}$ parts per million respectively.

In Series I. it has been shown that the whole of the milk collected from each of twenty separate cows contained in each case less than 25 parts per million of sediment. Two of the samples yielded positive results with the B. enteritidis sporogenes test with I cc. of the sample, and hence they infringed the suggested standard. But $I$ have no doubt that with sterile or scrupulously clean milking cans and strainers, proper provisions for preventing aerial contamination and other suitable precautions, milk need never contain spores of B. enteritidis sporogenes in $\mathbf{I}$ cc. of the sample.

None of the samples contained B. coli (or coli-like microbes) in ${ }^{\circ} \mathrm{I} \mathrm{cc}$. and only one in ' $I$ cc. As regards streptococci, some hesitation is felt in expressing too definite an opinion, as the milk from seemingly perfectly healthy cows, collected with special precautions to avoid external contamination, may sometimes contain numerous streptococci. But the suggested standard, it will be noted, is for this reason made extremely lenient.

It has been pointed out already that the conditions pertaining to the collection of samples of milk under Series I. do not, by any means, represent the acme of perfection, but accepting them for purposes of illustration as "controls" to Series II., III., IV. and V., it is to be noted that their relation to the suggested standards may be summed up as follows :-

$B$. enteritidis sporogenes test.- 10 per cent. of the samples actually infringed the standard; but 40 per cent., I 5 per cent. and 35 per cent. were 10 , Ioo, and 1000 times purer respectively as regards this test than the samples infringing the standard.

$B$. coli test. - None of the samples infringed the suggested standard. On the contrary 5 per cent., 25 per cent., 40 per cent., and $3 \circ$ per cent. were $100,1000,10,000$ and 100,000 times purer respectively as regards this test than the samples infringing the standard.

Volume of sediment (primary and secondary readings). - All the samples far more than passed the suggested standards.

Streptococcus test.- None of the samples infringed the standard tentatively suggested.

Microscopical examination of the sediment.-As previously explained, the interpretation of the results of the microscopical examination of the sediment is beset with difficulties.

Although Series I. yielded satisfactory results, I am unable to suggest, at the present time, any practicable standard as regards this test. 
Series II., III., IV. and V. in relation to the foregoing standards rank as follows :-

(1) $B$. enteritidis sporogenes test. $-50,45,30$ and 25 per cent. of the samples under Series II., III., IV. and $V$. respectively infringed the standard.

(2) B. coli test. -6o, $5 \circ, I_{5}$ and 25 per cent of the samples under Series II., III., IV. and V. respectively infringed the standard.

(3) Primary reading of sediment. $-35,25,20$ and 5 per cent. of the samples under Series II., III., IV. and V. respectively infringed the standard.

(4) Secondary reading of sediment.-35, 20, 20 and 5 per cent. of the samples under Series II., III., IV. and V. respectively infringed the standard.

As previously explained, the results obtained by $(a)$ the streptococcus test and $(b)$ the microscopical examination of the sediment do not lend themselves to precise comparative treatment; but considering the results under $(a)$ and (b) in conjunction with the results under ( 1$),(2),(3)$ and (4), there can be no doubt that series II. and III. stand last in order of merit.

It will perhaps be contended that if these standards were tentatively entertained as practicable, a large proportion of milk samples would be liable to be condemned. The word liable is used advisedly; because it would only be possible in practice to examine an inconsiderable proportion of the total number of samples of milk exposed for sale in London, and so the great majority, although unsatisfactory on the basis of the foregoing standards, would escape condemnation. But it must be remembered that Series II. and III. do not represent the average quality of milk exposed for sale in purveyors' and dairy shops. In the main, they were collected from poor neighbour hoods and from premises which the Council's inspectors knew to be illadapted for the sale of milk; the shop-keepers were often individuals who neglected the most elementary rules as regards cleanliness.

In respect of Series IV. it cannot be said that the stages leading up to the final delivery of milk to the consignee in churns at our railway stations are so satisfactory as to create any surprise that a by no means inconsiderable proportion of the samples proved to be unsatisfactory on bacteriological analysis.

As regards Series V., it might be contended, perhaps, that some of the well-known milk dealers are well-known rather by the magnitude of their business transactions than by the uniformly satisfactory biological quality of the milk they supply to consumers.

Lastly, if it be conceded that much of the milk at present sold in London is impure and ought to be condemned in the interests of public health, it is obvious that no standards would be of value in futuro which did not suffice to condemn many of the samples of milk now being sold.

\section{Description of the Methods used in the Bacteriological Examination of Milk} Samples. Measurement by Volume of the Apparent Filth in Milk.

Primary reading.- The sample of milk contained in a glass-stoppered bottle is shaken and several hundred cubic centimetres poured into the cylindrical sedimentation apparatus shown in fig. I (p. 156).

I cc. of formalin is next added to the contents of the cylinder and immediately afterwards more milk is added until the level of the $1000 \mathrm{cc}$. mark has been reached.

After twenty-four hours the volume of apparent filth in the milk is "read off" on the scale. This is called "primary reading," and it is nearly always in excess of the "secondary reading." While there is no fixed relation between the "primary and secondary readings," owing to the variable nature of the sediment in milk, it will, nevertheless, be found that the "primary 
readıng" is apt, within certain limits, to be about double that of the "secondary reading."

Secondary reading.-The centrifugal tube shown in fig. 2 is held under the outlet of the cylindrical sedimentation apparatus, the stopcock of the latter turned sharply on and off several times until all the deposit has been swept into the centrifugal tube. Distilled water $\left(+{ }^{\cdot} \mathrm{I}\right.$ per cent. $\left.\mathrm{Na}_{\mathbf{2}} \mathrm{CO}_{3}\right)$ is next added to the centrifugal tube up to the Io cc. mark. The tube is next placed in a good pattern hand centrifugal machine, and the handle of the machine rotated rapidly for two minutes. The tube is withdrawn and the volume of apparent filth "read off" on the scale. This is called the "secondary reading," and it is practically always less than (commonly about one-half) the "primary reading."

\section{Mucroscopical Examination of the Deposit.}

The liquid in the centrifugal tube is poured off : it will be found that this may be done without losing any of the sediment, which indeed lies wedged, as it were, at the foot of the narrow end of the tube. Distilled water $(+\cdot \mathrm{I}$ per cent. $\mathrm{N}_{2} \mathrm{CO}_{3}$ ) is added up to the ro cc. mark. By means of the alternate use of the copper wire (fig. 3) and glass pipette (fig. 4) the deposit is removed from the narrow end of the centrifugal tube, and dispersed throughout the diluting liquid.

The tube is again placed in the centrifugal machine and centrifugalised for another two minutes. For the second time the supernatant fluid is poured off, and by means of a suction apparatus (fig. 5) the liquid is still further reduced in amount until it stands at the ${ }^{\prime} 5 \mathrm{cc}$. mark on the scale.

The copper wire (fig. 3 ) is again brought into requisition in order thoroughly to mix the sediment. The glass pipette (fig. 4) is next used to draw off a portion of the sediment, and to transfer it to a watch glass.

Cover glass preparations ( $\frac{3}{4} \mathrm{in}$. by $\frac{3}{4} \mathrm{in}$.) are next made with $\circ \mathbf{I} \mathrm{cc}$. of the sediment, the pipette shown in fig. 6 being used for this purpose. With a platinum loop the sediment is spread as uniformly as possible over the surface of the cover glass.

The cover glass preparation represents $\circ$ I cc. (one-fifteenth part) of the sediment of $1000 \mathrm{cc}$. of milk diluted up to a constant amount, namely, ${ }^{\prime}{ }_{5} \mathrm{cc}$. That is, it represents one-fifteenth part of the total volume of filth in $1000 \mathrm{cc}$. of milk.

The foregoing is a definite procedure and can be repeated by any students of the subject. Indefinite methods in this connection are to be discouraged, as the results obtained cannot be repeated by separate workers, and so are apt to be of value only to the particular observer who is responsible for them.

The cover glass preparation is next "flamed," immersed in ether for five minutes, transferred directly to absolute alcohol for a few seconds, and, without wasbing, placed film downwards in freshly-prepared methylene blue solution $(6 \mathrm{cc}$. of the filtered saturated alcoholic solution of methylene blue, in $20 \mathrm{cc}$. of a $I$ in I0,000 solution of caustic potash) for not more than ten seconds.

After washing and drying, the preparation is mounted in Canada balsam in the ordinary way and is then examined with a one-sixth objective and a four ocular, the tube being drawn out to such an extent as to give a magnification of 460 diameters.

At least five "fields" from each quarter of the cover glass shouid be carefully examined.

Separate cover glass preparations may also be stained as for tubercle, in the following manner:-

After treatment with ether and alcohol, the preparation is stained for several 
minutes in hot carbol, fuchsin, washed, decolourised in 33 per cent. nitric acid, washed, and counter-stained with methylene blue. After washing, drying, and mounting, the preparation is examined for the presence of acidfast bacilli, with a one-tenth or one-twelfth oil immersion lens, in place of the one-sixth objective previously recommended. As already pointed out, failure to find acid-fast bacilli affords no convincing evidence of their real absence. Moreover, not all acid-fast bacteria are tubercle bacilli.

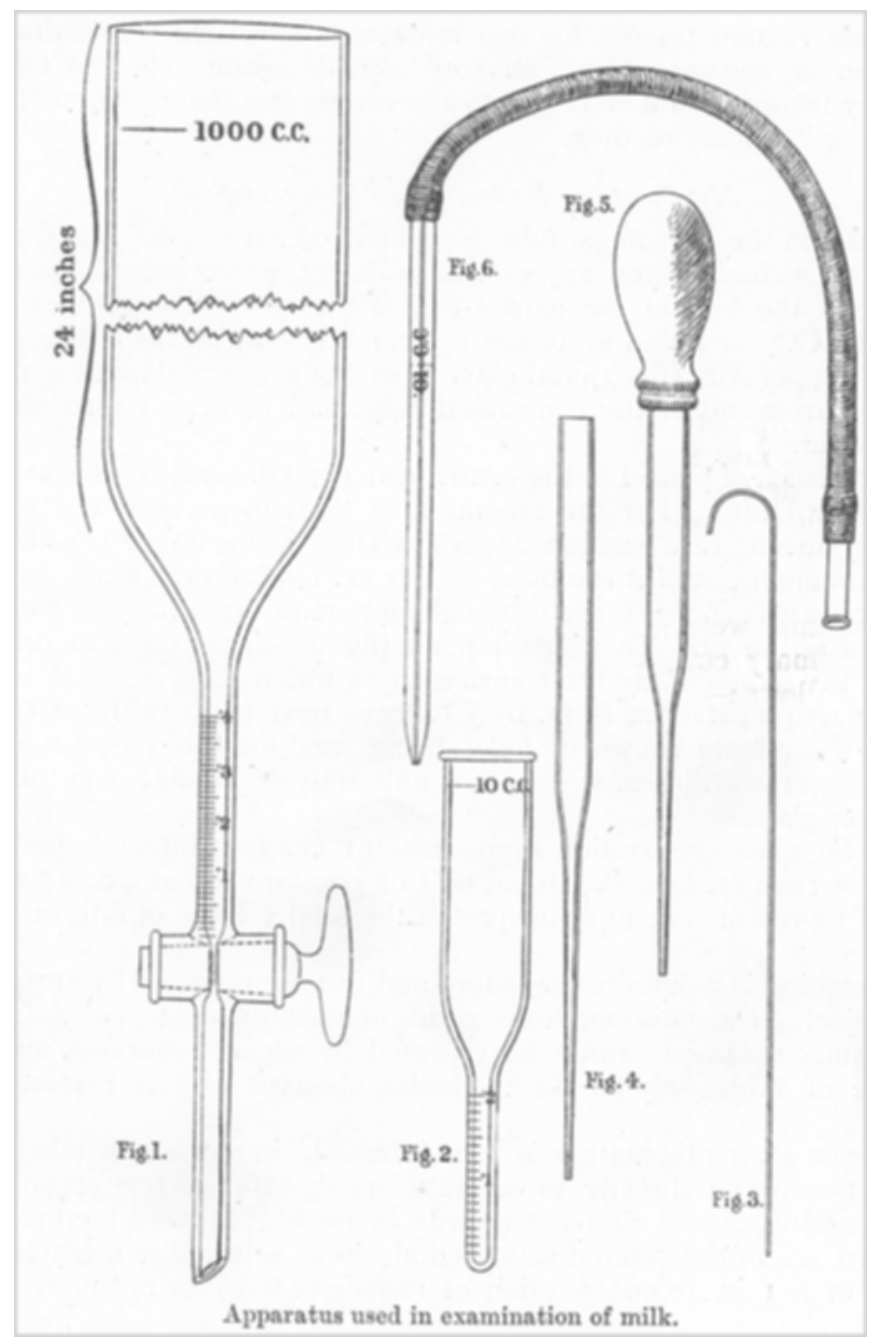

Cultural Tests.

Dilution.-Take six small conical Erlenmeyer's flasks, and add to each one $90 \mathrm{cc}$. of water. Plug the flasks with cotton wool, and sterilise in the steam steriliser at $100^{\circ} \mathrm{C}$. for one hour on two successive days. Label the flasks (1), (2), (3), (4), (5), (6). To flask (r) add Io cc. of the sample by means of a Io cc. sterilised pipette, and shake thoroughly. With a Io cc. sterilised pipette withdraw Io cc. of the liquid from flask (r) and add them to flask (2) and shake thoroughly. In the same way, withdraw ro cc. of the contents of 
flask (2) and add them to flask (3). Add ro cc. from flask (3) to (4), and Io cc. from flask (4) to (5), and finally Io cc. from (5) to (6). Dilution may of course be carried still further, but for ordinary purposes the above is quite sufficient. In this way a series of dilutions are obtained, having the following values :-

I cc. of dilutions (r), (2), (3), (4), (5), and (6) represents one-tenth, onehundredth, one-thousandth, one-ten-thousandth, one-hundred-thousandth, and one-millionth of a cubic centimetre of the sample.

O. I cc. of dilutions (I), (2), (3), (4), (5), and (6) represents one-hundredth, one-thousandth, one-ten-thousandth, one-hundred-thousandth, one-millionth, and one-ten-millionth of a cubic centimetre of the sample.

\section{B. Coli Test.}

Primary liquid cultures and secondary plate cultures method.-The bile-salt glucose peptone medium of $\mathrm{M}^{\circ} \mathrm{Conkey}$ was used for the primary cultures and a gelatine medium for secondary "plating" purposes. The procedure was as follows :-

Ten cc. of the milk were added by means of a sterile ro cc. pipette to a tube containing ro cc. of double strength bile-salt glucose peptone medium.

A sterile I cc. pipette was used for inoculation from the various dilutions in reverse order, i.e., I cc. from dilutions (6), (5), (4), (3), (2), and (I), were successively added to a series of bile-salt glucose peptone tubes.

Finally, with the same pipette I cc. of the undiluted milk was added to another bile-salt glucose peptone tube.

The cultures representing from $10 \mathrm{cc}$. to one-millionth of a cubic centimetre of the milk were next incubated at $37^{\circ} \mathrm{C}$. for two days.

All the primary cultures showing acid and gas formation were next subcultured as follows :-

A platinum loopful was transferred to ro cc. of sterile water, and, after shaking, a second platinum loopful was used to inoculate the secondary gelatine medium, the material being spread over the surface of the solid medium by means of a suitable sterile instrument.

The secondary gelatine plate cultures were incubated at $20^{\circ} \mathrm{C}$. for two days and the coli-like microbes sub-cultured in gelatine and "shake" cultures made. Those forming "gas" were tested in neutral red broth (for greenish-yellow fluorescence; in lactose peptone (for acid and gas formation); in broth (for indol formation); and in litmus milk (for acid clotting). Cultures were also made in a cane-sugar peptone medium for observations as regards gas production.

Primary plate culture method.-A gelatine medium or an agar medium (with or without the addition of one or another sugar) may be employed. But there is a convenience in using the Drigalski and Conradi medium, as this medium is specially suited for the isolation of streptococci, as also of the non-lactose fermenting group of $B$. coli.

The procedure in any case is the same. The plates are inoculated with - or cc. of the various dilutions and the material spread over the surface of the plates by means of a suitable sterile instrument. The plates are incubated at $37^{\circ} \mathrm{C}$. and after twenty-four to twenty-eight hours carefully examined. Selected colonies are sub-cultured in various media in the manner already described.

\section{Streptococcus Test.}

As previously explained, the Drigalski and Conradi medium is well adapted for the purpose in view. The plates are inoculated with $0^{\circ} \mathrm{I} \mathrm{cc}$. of the various dilutions and the material spread over the surface of the plates by means of a suitable sterile instrument. After incubation for twenty-four to 
forty-eight hours at $37^{\circ} \mathrm{C}$. the minute colonies are sub-cultured in broth The broth cultures are incubated for twenty-four to forty-eight hours at $37^{\circ} \mathrm{C}$. and then examined microscopically. If the results of the microscopic examination prove satisfactory, the streptococcus is subjected to the following tests:-

Nitrate broth tests (for observation as regards absence of ability to reduce nitrate to nitrite), neutral red broth test, under anaërobic conditions (for observation as regards the production of greenish-yellow fluorescence), litmus milk test (for observation as regards acid clotting); and the following tests for observation as regards acid production : lactose, saccharose, salacin, raffinose, mannite, and inulin.

An alternative method is to inoculate a series of lactose peptone (+ Liebig) tubes from the various dilutions. These tubes are incubated at $37^{\circ} \mathrm{C}$. for twenty-four to forty-eight hours. As the great majority of milk streptococci produce acid in a lactose medium, only those tubes which show an acid change need be studied. Microscopic preparations from the tubes showing development of acidity are next made to see whether streptococci, mixed or unmixed with other bacteria, are present. If streptococci are present, secondary plate cultures must be made and the microbes studied in pure culture. This method works fairly well if the streptococci are present in large numbers compared with other microbes. But under these conditions almost any method would yield satisfactory results.

\section{B. Enderitidis Sporogenes Test.}

The amounts of milk commonly used for cultural purposes for this test were as follows : I00 cc. 10 cc.; I cc.; 'I cc.; $\circ$ I cc.; and .001 cc. The Ioo cc. of milk is added to a large sterile tube; the ro cc. of milk to a large tube containing $3 \circ \mathrm{cc}$. of sterile milk; and the rest of the amounts to ordinary tubes containing $\mathrm{I} 5 \mathrm{cc}$. of sterile milk. The cultures are heated after inoculation, to $80^{\circ} \mathrm{C}$. for ten minutes for the lesser amounts and fifteen to twenty minutes for the larger amounts of milk. The cultures are incubated under anaërobic conditions, at $37^{\circ} \mathrm{C}$. and observatıons made as regards the "enteritidis change" after two days incubation.

\section{The Desirability of a Temperature Standard.}

It is well known that within a certain range of temperature the microbes in milk multiply very rapidly. In attempting to judge bacteriologically the purity of milk, there are two serious difficulties to be faced. The one is that samples of milk placed on sale necessarily show a wide variation as regards the time that has elapsed since milking. The second is that the temperature varies greatly during the year. The variations as regards time cannot reasonably be avoided; but the initial cooling of milk and its maintenance at a low temperature is merely a question of expense. It is perfectly true that above a certain temperature the increase in number of microbes in a milk is, for each increment of temperature, governed by the length of time the sample is stored; nevertheless, it is also known that belowe a certain temperature the influence of time may practically be discounted. For example, in the height of summer all samples of milk of initially good, bad, or indiff:rent biological quality are so influenced by the high temperature that it becomes merely a question of a few extra hours of storage when the sample, initially of satisfactory biological quality, will altogether eclipse, in its total microbial contents, the sample initially unsatisfactory bacteriologically. But in the depth of winter bacterial multiplication is to such an extent held in abeyance by the low temperature that time ceases to become an important factor, and the bacteriological results fairly gauge the degree of biological impurity of milk samples. 
It is recommended that, immediately after milking, the milk should be cooled rapidly below $10^{\circ} \mathrm{C}$., and maintained below this temperature. This is not a new suggestion, but many will regard it as the only satisfactory alternative to the humanisation of milk.

To consider it impracticable would be to lessen the value of some of the present tests of the bacteriologist.

A standard temperature might be enforced, either directly or indirectly, or in both ways. For example, a milk might be condemned if its temperature were above $10^{\circ} \mathrm{C}$. It might also be condemned because it transgressed the limits of certain bacteriological standards either due to gross pollution or to such culpable neglect of regulations as regards temperature as would allow the bacteria resulting from a less contamination to multiply abundantly in the milk. Nevertheless, it is not, of course, contended that in the latter case the milk would be necessarily as objectionable as in the former case.

The following experiments show (I) that at a high temperature the number of B. coli and streptococci increase in milk to an enormous extent within twenty-four hours; and (2) that at a low temperature milk may be stored for twenty-four hours without any serious increase in the number of these microbes.

(1) Effect of storage for twenty-four hours at a high temperature.-Five samples of milk were examined bacteriologically. They were then placed in the incubator at a temperature of $20-22^{\circ} \mathrm{C}$, and re-examined after an interval of twenty-four hours. All five samples contained, to start with, ten B. coli (or coli-like microbes) per cc. After twenty-four hours the number of B. coli (or coli-like microbes) had increased to 100,000 per $\mathrm{cc}$. in two of the samples and to I0,000 per $\mathrm{cc}$. in the remaining three samples. As regards streptococci, the increase was at least one-hundredfold to one-thousandfold under the same conditions.

The results, as regards the $B$. enteritidis sporogenes test, was the same after as before incubation, $i . e$., there was no detectable increase in the number of spores of this anaërobe.

(2) Effect of storage for teventy-four hours at a low temperature.-In the first experiment of this series, five samples of milk were examined bacteriologically, and then maintained at a temperature of $7-10^{\circ} \mathrm{C}$, and re-examined after an interval of twenty-four hours. Before storage, samples 3 and 4 contained $B$. coli (or coli-like microbes) in 10 cc. but not in I cc. Samples I, 2 and 5 yielded negative results even with Io cc. of the sample. After storage, samples $2,3,4$ and 5 yielded negative results even when using rocc. for cultural purposes. In sample $\mathbf{I}$, however, $\mathbf{B}$. coli (or coli-like microbes) were present in $\mathrm{I} /$ Ioth but not in $\mathrm{I} / \mathrm{I}$ ooth cc.

As regards streptococci, before storage, samples $\mathrm{I}, 2,3,4,5$ gave respectively the following results: negative ${ }^{\prime} \mathrm{I}$ cc.; $+{ }^{\prime} \mathrm{I}$ cc. ; negative ${ }^{\prime} \mathrm{I} \mathrm{cc}$. ; + I cc. $;+\circ$ o cc. After storage, the results (in sequence) were: a very few in $I$ cc.; a very few in $O I$ cc.; a few in $I$ cc.; a few in $I$ cc.; a few in -I cc.

In the second experiment, five samples of milk were examined bacteriologically before and also after twenty-four hours' storage at a temperature of 7-I $\mathrm{I}^{\circ} \mathrm{C}$. Before storage the $\mathrm{B}$. coli results were respectively as follows: +10 cc. ; + I0 cc. ; - I0 cc. ; + I cc. ; - Io cc. After storage the results were respectively: + ro cc. ; + 10 cc. ; + IO cc. + I cc. + Io cc.

Before storage, the streptococcus results were respectively as follows: - ' I cc. ; - ' I cc. ; + ' I cc. ; + ${ }^{\circ}$ I cc. ; + ' I cc.

After storage, the results were respectively : - 'I cc.; -. 'I cc.; + 'I cc. ; + I cc. ; + I cc.

In the third experiment, five samples of milk were examined bacteriologically before and also after twenty-four hours' storage at a temperature of $6 \cdot \mathrm{I}-7 \cdot 78^{\circ} \mathrm{C}$. 
Before storage, the $\mathrm{B}$. coli results were respectively as follows: $+\mathbf{I} \mathrm{cc}$.; - Io cc. ; + I cc.; + I cc. ; + Io cc.

After storage, the results were respectively : + 'I cc. ; + Io cc. ; + 'I cc. ; + I cc. ; + Io cc.

Before storage, the streptococcus results were respectively as follows: + I cc. ; + OI cc. ; + I cc. ; + I cc. ; + OI cc.

After storage, the results were respectively : + 'I cc. ; + or cc. ; + or cc. ; + . I cc. ; + or cc.

Regarding twenty-four hours as an over estimate of the length of time that should reasonably be allowed between the milking of the cow and selling her milk, and assuming the practicability of a standard below $10^{\circ} \mathrm{C}$., no hesitation is felt in expressing the opinion that the bacteriologist could always measure with reasonable accuracy the degree of undesirable pollution of a milk and would be justified in objecting to samples transgressing a fixed standard of purity. Failure on the part of those engaged in the milk trade ( $\mathrm{r}$ ) to attend to the ordinary rules of cleanliness; (2) to refrigerate milk and keep it at a low temperature; and (3) observe a twenty-four hours' maximum for storage would, it is admitted, lead to the condemnation on bacteriological grounds of many samples of milk. But it must be remembered that it is not sought to establish the purity of a pure article of food, but to improve the quality of a commodity already under the ban of suspicion. In a prospective and perhaps not too serious a sense the bacteriologist may be expected to discover eventually some magical test which will estimate the "disease value" of every sample of milk. Meanwhile, it may be possible to improve pro. gressively the biological qualities of our milk supply without serious injury to trade by using the existing bacteriological tests for measuring the degrees of excremental and other kinds of uudesirable pollution of food.

\section{The Bacteriological Examination of "Fore" Milk.}

Although it is customary to reject the "fore" milk, the following account of the results of the bacteriological examination of "fore" milk collected with special precautions and under favourable conditions may prove of interest.

The samples were collected in sterile bottles, cooled by means of ice, conveyed rapidly to the laboratory and examined at once. The cow's udder and teats were carefully washed and the milker washed his hands before milking.

Experiment 1.-In this experiment the fore-milk was derived from four separate healthy cows. The total volume was $275 \mathrm{cc}$. The results were as follows :-

$B$. enteritidis sporogenes test.-Negative result Ioo cc. of the sample.

B. coli test.-Negative result to cc. of the sample.

Streptococcus test.-No streprococci in $\frac{1}{10}$ cc.

Experiment $I I$. - In this experiment the fore-milk was derived from five separate healthy cows. The total, volume was $47^{\circ} \mathrm{cc}$. The results were as follows :-

$B$. enteritidis sporogenes test.-Negative result $\mathrm{r} 00 \mathrm{cc}$. of the sample.

$B$. coli test.-Negative result to cc. of the sample.

Streptococcus test.-Here the result was widely different from Experiment I. The number of streptococci was about 200 per cc. The biological attributes of twenty of these streptococci are given in the accompanying table. It will be noted that they all belong to one of two groups, namely-a positive salicin group and a negative salicin group. In all other respects they were indistinguishable. Equal amounts of broth cultures of these streptococci were mixed together and five mice were severally inoculated with $\mathrm{I}$ cc. of the mixture. The mice remained alive and were apparently quite unaffected.

Experiment $I I I$. - In this experiment the fore-milk was derived from four 
separate healthy cows. The total volume was $570 \mathrm{cc}$. The results were as follows: :-

$B$. enteritidls sporogenes test.-Negative result roo cc. of the sample.

$B$. coli test.-Negative result ro cc. of the sample.

Streptococcus test. - No streptococci in $\frac{\mathrm{T}}{\mathbf{1} 0} \mathrm{cc}$.

Morphological and Biological Characters of Streptococci isolated from Fore-milk.

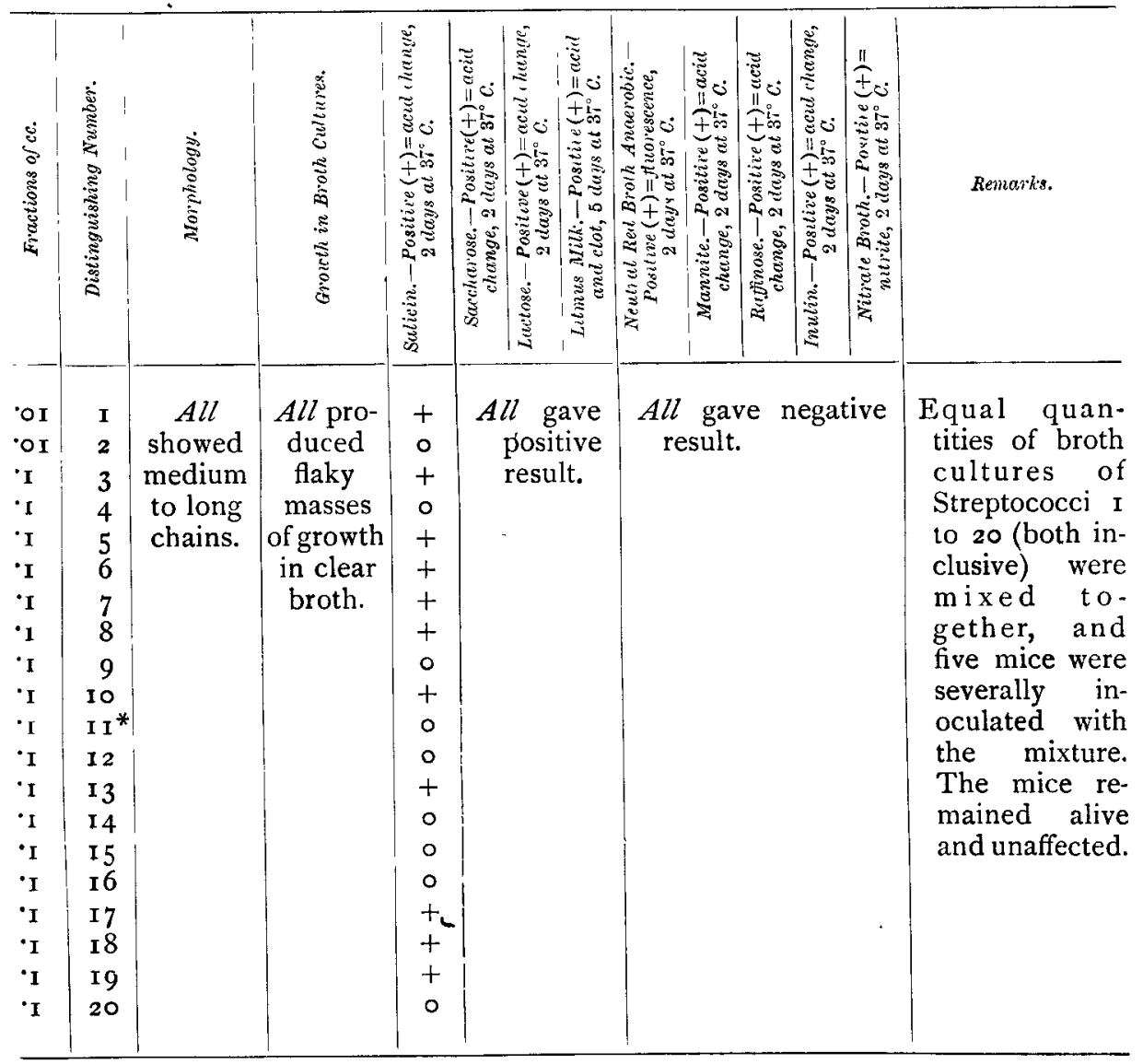

It will be noted that in all the three experiments no spores of $B$. enteritidis sporogenes were found in $100 \mathrm{cc}$., and no B. coli in $10 \mathrm{cc}$.

As in these three experiments the "fore" milk was derived from four, five, and four cows, it may be asserted with some degree of confidence that when B. enteritidis sporogenes and B. coli are found in milk they are in all probability derived from external sources of pollution, and are not present in the milk as it leaves the udder. Given, therefore, conditions which inhibit the multiplication of B. coli (e.g., refrigeration), both these tests (B. coli and B. enteritidis sporogenes tests) are of value in gauging the degree of contamination of a milk sample which has taken place. As regards the streptococcus test the case is different. In two of the experiments the results were negative; but in one of the three experiments streptococci abounded, and so it cannot be said that the streptococci found in samples of milk are necessarily derived 
from sources external to the udder. On the other hand, it seems equally clear that streptococci are not habitually present in milk as secreted, or in the teats or ducts of the udder, since in Experiments I. and III. no streptococci were found, although the samples were derived from the first flow of milk from the teats of four cows in both instances.

It is important also to note that the streptococci in Experiment II. were all of one or other of two species. If on further work it should turn out to be the case that all or most of the streptococci derived from the teat or udder of healthy cows belong to one or other of these two groups, and that these groups are seldom represented in the excrement of men and the lower animals, then it would be possible in the examination bacteriologically of sample of milk to draw a distinction between those streptococci which were probably of udder origin and those which in all probability were derived from excremental pollution.

In summary it may be said that so far as may be judged from the foregoing experiments, B. coli and B. enteritidis sporogenes are absent and streptococci may or may not be present in "fore" milk, which is universally conceded to be likely to be the most impure bacteriologically of any sample of milk taken at any stage throughout the whole milking.

\section{LOUPING-ILL AND BRAXY. GENERAL REPORT OF THE DEPARTMENTAL COMMITTEE APPOINTED BY THE BOARD OF AGRICULTURE*}

IN the month of December I90 r the President of the Board of Agriculture appointed Professor Hamilton, Aberdeen University, Dr J. M. M'Call, Assistant Veterinary Officer, Board of Agriculture, and Mr E. G. Wheler, Alnwick Castle (with Mr R. B. Greig as Secretary) to be a Committee to inquire into louping-ill and braxy. The Committee has now issued a complete Report, of which the following forms Part I. ${ }^{1}$

\section{SECTION I.-LOUPING ILL (CHOREA PARALYTICA OVIS).}

FIRST LOUPING-ILL SEASON-I9O2.

At the first meeting of the Committee, held on I 8 th January I902, we discussed the line of action which should be adopted, and came to the conclusion that the first thing to be done was to obtain reliable knowledge of the symptomatology and pathology of the disease, and to ascertain whether any of the liquids or tissues of the sheep were charged with a morbific agent, and whether they were possessed of contagious properties.

Before taking up our quarters at the Kielder Station in the spring of the year 1902, we made arrangements to have sick or dead animals brought in to us, and at no time have we had a lack of material to work upon. Our object at first was, as much as possible, to make those cases brought in alive the object of particular study, as by that means a connected record would be obtained from personal observation of the course of the disease and the appearances characteristic of it afier death.

1 Part II. ("Details of Investigation") and Part III. ("Summary of Suggestions") are published separately, price $4 \mathrm{~s}$. and $2 \mathrm{~d}$. respectively, and may be obtained from Messrs Wyman \& Sons, Ltd., Fetter Lane, E.C. 